\title{
Perioperative isoproterenol infusion in a patient with Brugada syndrome
}

\author{
Ying-Chun Lin, MD $\cdot$ Chien-Chuan Chen, MD $\cdot$ Cho-Chi Yang, MD
}

Received: 23 December 2016/Revised: 9 January 2017/Accepted: 23 January 2017/Published online: 1 February 2017

(C) Canadian Anesthesiologists' Society 2017

\section{To the Editor,}

We report the novel use of perioperative isoproterenol in a 38-yr-old 65-kg man undergoing emergency laparoscopy for an abdominal stab wound. He was suspected to have Brugada syndrome (BrS) after his preoperative electrocardiogram (ECG) demonstrated pathognomonic characteristics, including $\mathrm{J}$ elevation $\geq 0.2 \mathrm{mV}$ and a coved-type $\mathrm{ST}$ segment followed by a negative $\mathrm{T}$ wave in leads V2 and V3 (Figure A). He reported no other clinical features of $\mathrm{BrS}$ (i.e., unexplained syncope, nocturnal agonal respiration, family history of sudden cardiac death at $<45 \mathrm{yr}$ ), nor did he have any known history of ventricular fibrillation or polymorphic ventricular tachycardia. ${ }^{1}$ His laboratory investigations and chest radiography were otherwise normal.

On arrival to the operating room, he was alert and oriented. Standard monitors ${ }^{2}$ revealed a pulse rate of 100 beats $\mathrm{min}^{-1}$, blood pressure $100 / 62 \mathrm{mmHg}$, room air pulse oximetry $100 \%$, and body temperature $36^{\circ} \mathrm{C}$. A defibrillator was readily available if a malignant arrhythmia occurred.

He was induced with midazolam $2.5 \mathrm{mg}$, fentanyl 150 $\mu \mathrm{g}$, propofol $120 \mathrm{mg}$, and rocuronium $50 \mathrm{mg}$. After securing his airway, and with an abundance of caution (considering that the $\mathrm{CO}_{2}$ pneumoperitoneum might enhance his arrythmogenicity), we prophylactically initiated a continuous isoproterenol ${ }^{5}$ infusion 0.004 to

Y.-C. Lin, MD · C.-C. Chen, MD · C.-C. Yang, MD ( $ه)$

Department of Anesthesiology, Mackay Memorial Hospital,

Taipei, Taiwan

Y.-C. Lin, MD · C.-C. Chen, MD · C.-C. Yang, MD

Mackay Medical College, Taipei, Taiwan

C.-C. Chen, MD

Mackay Medicine Nursing and Management College, Taipei, Taiwan
$0.005 \mu \mathrm{g} \cdot \mathrm{kg}^{-1} \cdot \mathrm{min}^{-1}$ General anesthesia was maintained with sevoflurane, with additional rocuronium and fentanyl as needed. A liver laceration was subsequently repaired, after which the neuromuscular blocking agent was reversed by neostigmine $2.5 \mathrm{mg}$ and glycopyrrolate $0.5 \mathrm{mg}$, and he was uneventfully extubated. The estimated blood loss was $350 \mathrm{~mL}$, and total fluid (crystalloid) given was 660 $\mathrm{mL}$. His heart rate throughout the procedure was $60-100$ beats. $\min ^{-1}$ without any atrial or ventricular arrhythmia.

An ECG obtained in the postanesthesia care unit (while the isoproterenol was still infusing) showed significantly reduced ST elevation (Figure B). He was subsequently transferred to the intensive care unit for continued postoperative monitoring. The isoproterenol was discontinued seven hours later, after normalization of the ST segment (Figure C). Thirty-one hours after discontinuation, typical J point and coved ST segment elevation reappeared on lead V2 (Figure D). One month later, the patient underwent an electrophysiological study (EPS) during which sustained ventricular tachycardia and ventricular fibrillation were induced. The diagnosis of $\mathrm{BrS}$ was confirmed, and an intracardiac defibrillator (ICD) was implanted to prevent sudden cardiac death.

Brugada syndrome, an inherited autosomal dominant cardiac disease, is one of the leading causes of sudden death in young men without structural cardiac defects. ${ }^{3}$ Patients with $\mathrm{BrS}$ are vulnerable to life-threatening ventricular arrhythmia. ${ }^{4}$ Symptomatic BrS patients with a spontaneous type 1 ECG pattern (described above and in the figure) should undergo ICD implantation. In addition, an ICD should be considered for asymptomatic BrS patients if an EPS induces ventricular tachyarrhythmia.

When a patient with a suspected type 1 Brugada ECG pattern who has not been fully evaluated and is not receiving any therapy presents in need of an emergent operation, medications that interact with cardiac electrical 
Figure Sequential

electrocardiographic changes in a patient with Brugada syndrome given a prophylactic continuous isoproterenol infusion. (A) Preoperative electrocardiogram (ECG) shows a typical type 1 Brugada pattern. with $\mathrm{J}$ elevation $\geq 0.2 \mathrm{mV}$ and a coved-type ST segment followed by a negative $\mathrm{T}$ wave in leads V2 and V3. (B) After two hours of isoproterenol infusion, the ST elevation in ECG had reduced significantly. (C) After seven hours of isoproterenol infusion, the ECG was normal. (D) At $31 \mathrm{hr}$ after discontinuing the isoproterenol, typical J point and coved ST segment elevation reappeared on lead V2

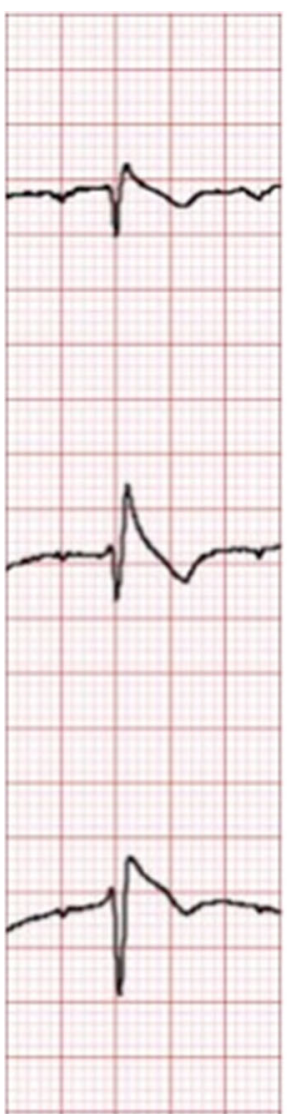

(A)

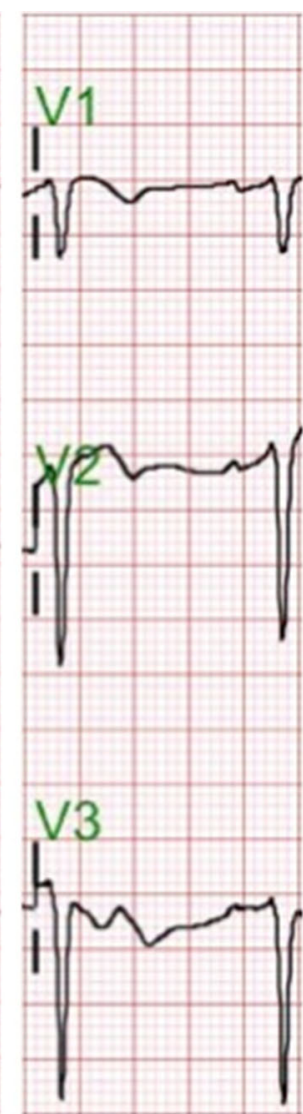

(B)

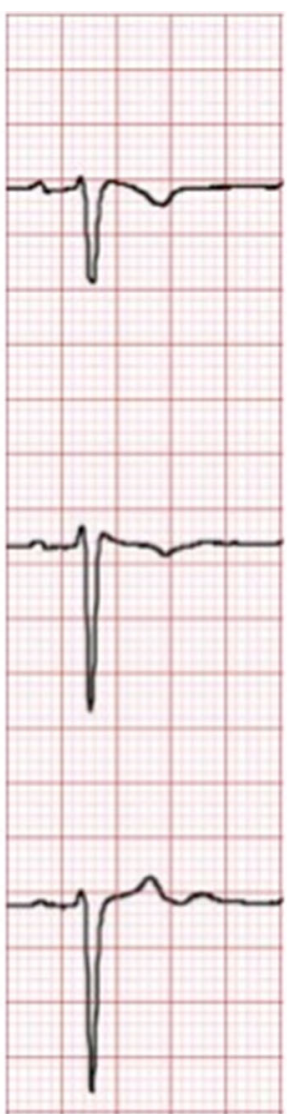

(C)

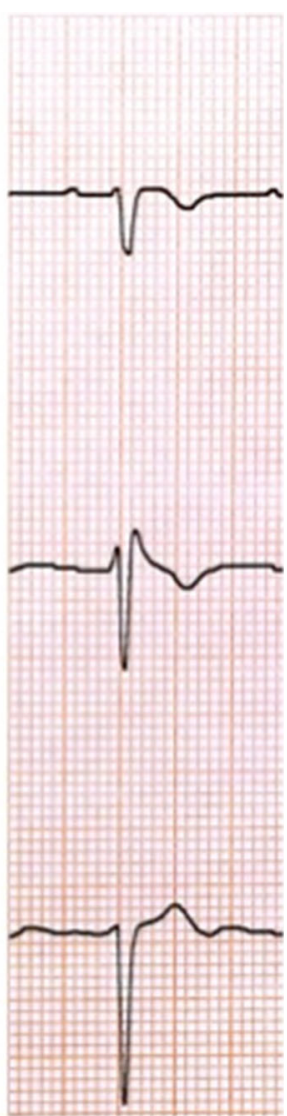

(D) activities may be the only preventive therapeutic option. Sodium channelopathies linked with $\mathrm{BrS}$ result in the $\mathrm{J}$ point elevation and ST segment changes because of a prominent, transient, outward current-mediated notch and loss of the epicardial action potential dome. ${ }^{5}$ By increasing the calcium current, the $\beta$-agonist isoproterenol may restore the action potential dome, thus normalizing the ST segment. ${ }^{5}$

Perioperative infusion of isoproterenol for preventing malignant ventricular arrhythmias has not been previously reported. In our patient, low-dose isoproterenol temporarily diminished the ST segment abnormalities. Although anesthesia is generally considered relatively safe in these patients, ${ }^{3}$ this novel low-dose isoproterenol infusion may offer further safety for those with uncontrolled $\mathrm{BrS}$ who require emergent operations. Whether this approach prevents ventricular arrhythmias requires further study.

Acknowledgements The authors thank the Departments of the Cardiovascular System, General Surgery, and Anesthesiology of MacKay Memorial Hospital for their support throughout the patient's medical care. We also thank Tun-Pang Chu and Yueh-Hung Lin for providing high-quality medical care and commenting on the manuscript review.

Authors' disclosure None of the authors received funding from any sources. None of the authors has conflicts of interest to report. All the authors are members of the Anesthesiology Department in Mackay Memorial Hospital.

Editorial responsibility This submission was handled by Dr. Hilary P. Grocott, Editor-in-Chief, Canadian Journal of Anesthesia.

\section{References}

1. Vohra J, Rajagopalan S, CSANZ Genetics Council Writing Group. Update on the diagnosis and management of Brugada syndrome. Heart Lung Circ 2015; 24: 1141-8.

2. Merchant $R$, Chartrand D, Dain $S$, et al. Guidelines to the practice of anesthesia - revised edition 2016. Can J Anesth 2016; 63: 86112.

3. Smith $D$, Martz $D G$. Brugada syndrome: a review of peri-operative 2: 1019.

4. Postema PG, van Dessel PF, Kors JA, et al. Local depolarization abnormalities are the dominant pathophysiologic mechanism for type 1 electrocardiogram in Brugada syndrome a study of electrocardiograms, vectorcardiograms, and body surface potential maps during ajmaline provocation. J Am Coll Cardiol 2010; 55: 789-97.

5. Jongman JK, Jepkes-Bruin N, Ramdat Misier AR, et al. Electrical storms in Brugada syndrome successfully treated with 15: 151-5. management for the anesthesiologist. Int J Clin Anesthesiol 2014; isoproterenol infusion and quinidine orally. Neth Heart J 2007; 